\title{
Taylor Visits Africa
}




\title{
WP/15/258
}

\section{IMF Working Paper}

\section{Taylor Visits Africa}

\author{
by Carlos Eduardo Goncalves
}

IMF Working Papers describe research in progress by the author(s) and are published to elicit comments and to encourage debate. The views expressed in IMF Working Papers are those of the author(s) and do not necessarily represent the views of the IMF, its Executive Board, or IMF management.
I N T E R N A T I O N A L
$M O N E T A R Y$
F U N D 


\title{
IMF Working Paper
}

Research Department and Strategy, Policy, and Review Department

Taylor visits Africa*

Prepared by Carlos Eduardo Goncalves

Authorized for distribution by Prakash Loungani and Catherine Pattillo

December 2015

\section{IMF Working Papers describe research in progress by the author and are published to elicit} comments and to encourage debate. The views expressed in IMF Working Papers are those of the author and do not necessarily represent the views of the IMF, its Executive Board, IMF management, or DFID

\begin{abstract}
Many low-income countries do not use interest rates as their main monetary policy instrument. In East Africa, for instance, targeting money aggregates has been pretty much the rule rather than the exception. Nevertheless, these targets are seldom met and often readjusted according to the economic environment. This opens up the possibility that central banks are de facto pursuing a strategy more akin to a Taylor Rule. Estimations of small-scale models for Kenya, Uganda and Tanzania suggest that these self-styled "monetary targeters" are respecting the Taylor Principle, that is are on average increasing nominal interest rates more than proportionally to inflation. Nevertheless, steep deviations from the Taylor Rule have taken place in Kenya and Tanzania. In Uganda, these errors are much smaller, in fact similar in size to Taylor Rule deviations found for Brazil. More surprisingly, they are smaller than South Africa's, the continent's sole long-term inflation targeter.
\end{abstract}

JEL Classification Numbers: E43, E50

Keywords: Neutral interest rates, central bank, inflation target

Author's E-Mail Address: cgoncalves@imf.org

\footnotetext{
* I thank Andy Berg, Bernardo Guimaraes and the participants in the RES-DM, African Department seminars for their comments.
} 


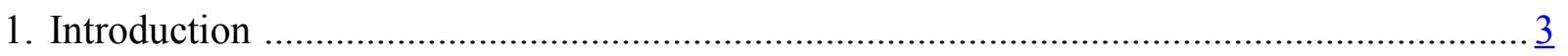

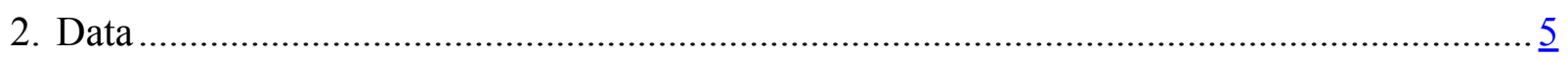

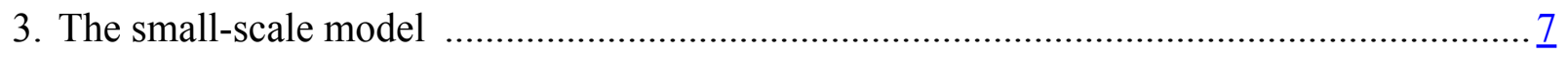

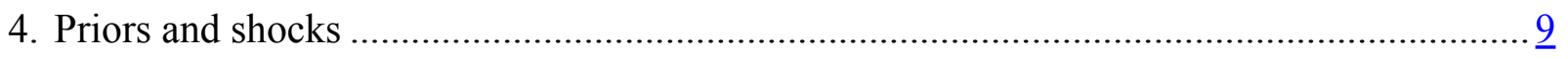

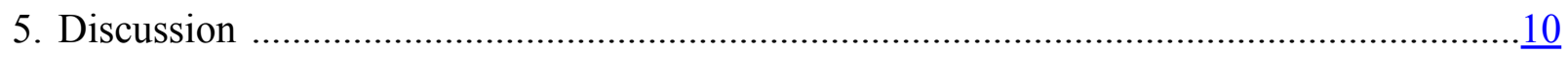

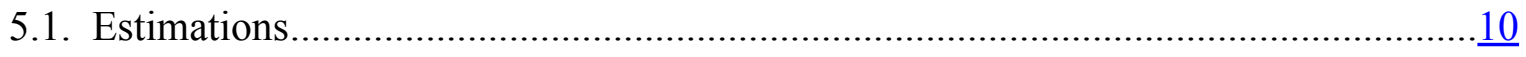

5.2. Estimating the neutral rate instead of demeaning by the average ............................13

5.3. Taylor Principle vs Taylor Rule ...................................................................

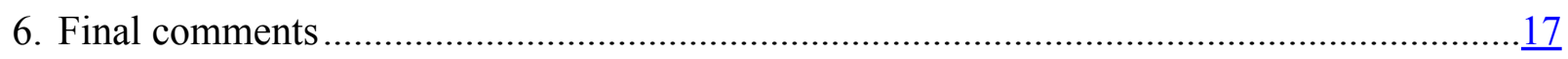

\section{Tables}

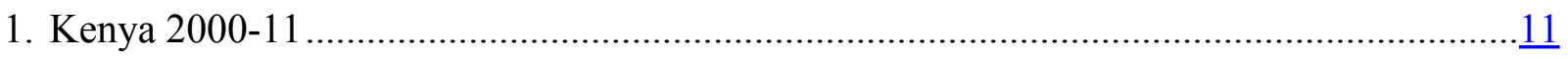

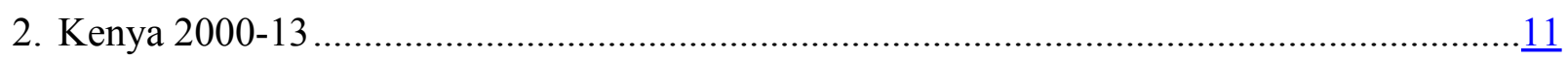

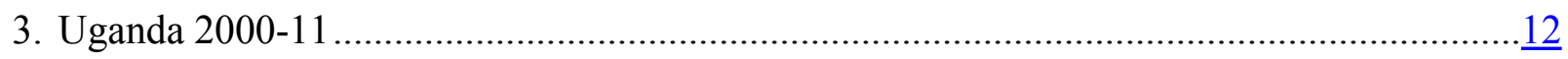

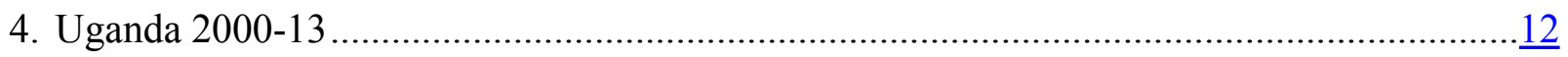

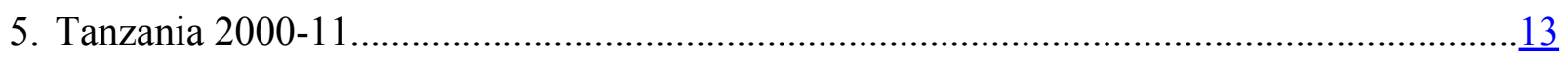

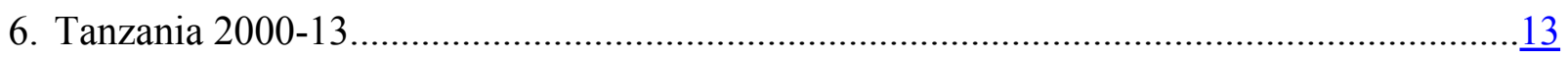

7. Estimating neutral rates instead of demeaning ........................................................ 14

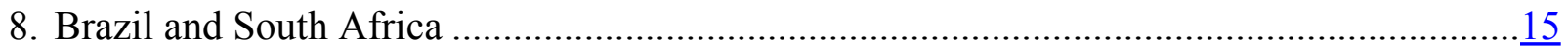

Figures

1. Tanzania interest rates in the 1990 s (red line is average) . ............................................

2. Uganda interest rates in the 1990s (red line is average) ............................................. 7

3. Normalized Taylor Rule's Residuals ..................................................................

4. Normalized Taylor Rule's Residuals - Brazil and Uganda...............................................16

5. Normalized Taylor Rule's Residuals - Uganda and South Africa .................................... 16 


\section{Introduction}

Currently, most of Emerging and Developed Economies use interest rates as their main monetary policy instrument, whether or not they have a formal Inflation Target framework in place. But that is not the case when it comes to low income countries (LICs), which still resort to pegs and money targeting to a great extent. In this paper, I investigate the behavior of monetary policy in three low-income African countries - Kenya, Tanzania and Uganda - that have formally set money targets as an intermediate means of achieving inflation stabilization goals until very recently. The core of the paper can be summarized in a simple question: "is it the case that by targeting money, these countries have ended up implementing a Taylor Rule that respects the Taylor Principle?"

Mankiw (2002) asks a similar question about U.S monetary policy during the nineties. The Federal Reserve did not explicitly follow a Taylor Rule nor had a Inflation Target regime in place in the 90s. But Mankiw shows that the FED policy decisions under Greenspan could be mimicked by a simple Taylor Rule including inflation and unemployment deviations. In Friedman's (1953) words, Mankiw's point is that Greenspan steered monetary policy as if he was mechanically implementing a Taylor Rule. The same question can be raised for East African countries' de jure monetary targeters: to what extent do their policies resemble a Taylor Rule that respects the Taylor Principle, that is, with nominal interest rates rising more than proportionally to inflation? This is the first question I tackle here.

Of course monetary policy is not set in stone and can change through time. In the case of East Africa, Berg et al (2013) identify a change in monetary policy's response after central banks from Kenya, Rwanda, Uganda and Tanzania met in October 2011 and agreed to tighten monetary conditions. The authors then go on to argue that monetary transmission channels proved not to be a problem: inflation did decline in the following years as monetary 
policy became arguably more focused on bringing it down.

In principle, however, there are two possible interpretations for their findings: (i) Central Banks (CBs) changed their reaction functions after the October 2011 meeting, or (ii) the meeting did not lead to any meaningful parameter change, the response of monetary policy being stronger simply because inflation had become too high.

Favoring (i), around this date two of the three central banks in question announced changes in their operational frameworks. The Bank of Uganda announced a move towards "inflation targeting lite" in July 2011, and in September of the same year the Central Bank of Kenya clarified its procedures and emphasized its base rate as the reference for overnight bank borrowing. Even the Bank of Tanzania, with its strict adherence to money aggregates' objectives, stated that its prime rate signalled the monetary policy stance.

So does hard empirical evidence support the thesis of a decisive turn in monetary policy in these countries after 2011? This is the second issue I address.

Finally, the third question I raise is: even if the Taylor Principle holds on average, how tightly linked are actual interest rates to the interest rates derived from the estimated Taylor Rules? Large deviations would be a signal of de facto monetary targeting, whereas small deviations would be more consistent with the idea of a gradual transition to interest rates instruments.

With that in mind, the empirical strategy I follow is to estimate small-scale semistructural models with Bayesian techniques for each country, using two different time spans: one beginning in 2000 and ending in 2011, and the other ending in 2013. If parameters in CBs reaction function change significantly after including the eight additional observations, claims of strutuctural change in 2011 would then have the backing of the data.

In a nutshell, the model estimated is a simplified version of the now famous SmetsWouters $(2003,2007)$ formulation and is comprised of three main equations: an IS curve, 
a Phillips curve and a Taylor Rule. Of particular interest in this paper is the coefficient multiplying the inflation term in the Taylor Rule. If it is estimated to be greater than one, then the so-called Taylor Principle holds even under money targeting. And if it increases after 2011, then assumption (i) associated with the Berg et al (2013) narrative would be a good description.of the behavior of central banks.

\section{Data}

The data sources used here are basically two: IFS ${ }^{1}$ and countries central banks' statistics for different measures of interest rates. Unfortunately, for most LICs, quarterly data on consumption, investment and hours worked do not exist. That is the reason why the estimation of a full-scale Smets-Wouters model is not pursued here. Instead I rely on a small-scale model using only inflation, a measure of output gap based on real quarterly GDP and interest rates as observable variables.

Inflation is given by quarterly variation in the CPI index and the output gap comes from applying Hodrick-Prescott filter to the log of real quarterly GDP. The sample goes from 2000 to 2013. For the last quarter of 2013, GDP data on Tanzania is lacking, though. I filled in this blank by applying the annual growth rate for Tanzania in 2013 reported in the WEO (April, 2015) to the GDP level for the last quarter of 2012.

Conceptually, one would like to use Central Bank's Monetary Policy Rate (CBR) in the estimated Taylor rules, but since these countries were (are?) until very recently officially targeting money, CBRs are only available for very short periods of time. For example, proper CBRs for Uganda are available only after 2011, and for Kenya only after 2006. Hence, three other interest rate measures are used: the "lending rate", the "3-month T-bill rate" and the

\footnotetext{
${ }^{1}$ Some of data retrieved from IFS, mainly output data for longer periods, is not publicly available.
} 
"interbank rate". The assumption is that these rates should be positively correlated with the "implicit" CBRs endogenously determined by the money instrument.

Data in IFS-EDSS goes further back in time until the beginning of the nineties, but resorting to this larger dataset has an important drawback: when one includes the nineties, there is a clear declining trend in many of the interest rates measures. Since all data used to estimate the model enter as deviations from steady state (proxied by the average of the variable), trends pose a big problem: by demeaning, one would end up with interest rates always above their steady-state levels for the earlier part of the sample, and with interest rates always below this value for the more recent periods. Monetary policy tightness would then be explained by a time trend: tight at the beginning and lax at the end of the sample. This is not reasonable since one does not observe a similar trend in inflation rates.

Fig.1: Tanzania interest rates in the 1990s (red line is average)

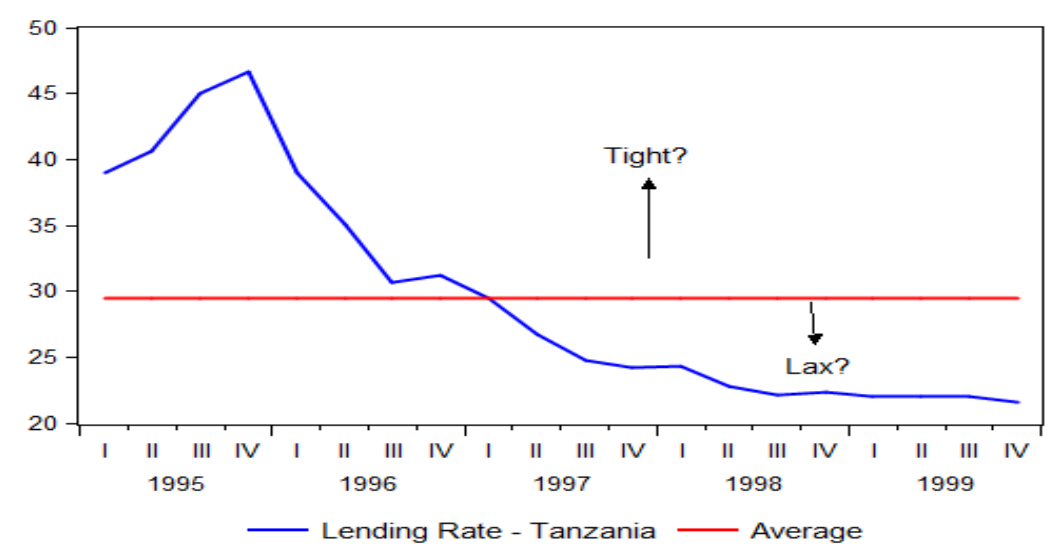


Fig 2: Uganda interest rates in the 1990s (red line is average)

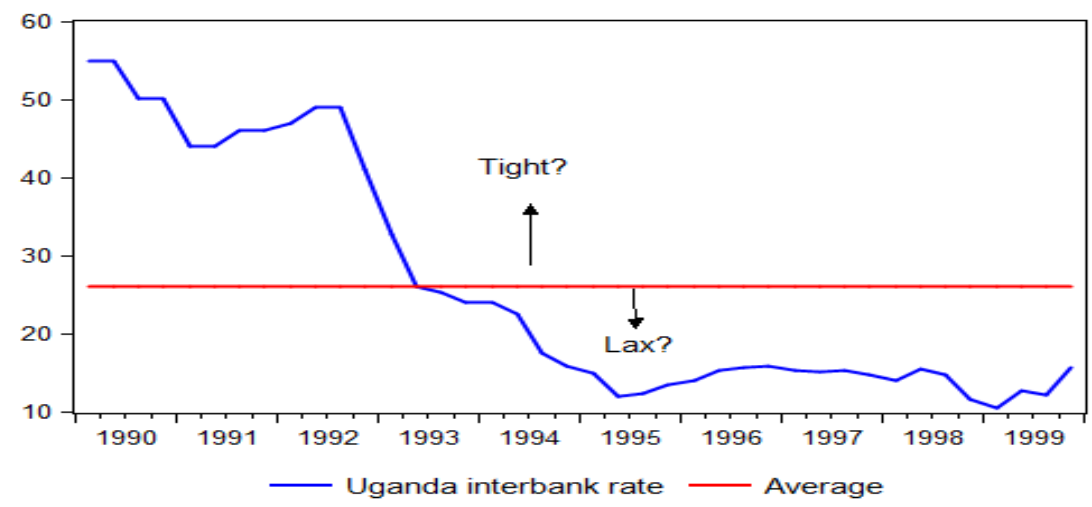

Demeaning of interest rates can also be achieved by jointly estimating a neutral rate of interest for the model using the Kalman Filter. I use this approach as a robustness check.

\section{The small-scale model}

The model to be estimated here is comprised of three main equations and three stochastic processes describing the dynamics of exogenous shocks.

The IS curve

Similarly to the standard New-Keynesian model, the output gap at $t, h_{t}$, is assumed to be a function of: (i) the expected output gap for $t+1$,(ii) ex-ante real interest rates, $i_{t}-\pi_{t+1}^{e}$ and (iii) a shock, $\epsilon h_{t}$ (a transitory increase in government spending, for instance).

$$
h_{t}=\alpha \cdot h_{t+1}^{e}+\theta \cdot\left(i_{t}-\pi_{t+1}^{e}\right)+\epsilon h_{t}
$$

Since $i_{t}-\pi_{t+1}^{e}$ is in fact equal to $\left[\left(i_{t}-\pi_{t+1}^{e}\right)_{a c t u a l}-\overline{\left(i_{t}-\pi_{t+1}^{e}\right)}\right]$, equation (1) is telling us that a steady state with zero output gap is consistent with actual interest rates equal to its steady-state (or neutral) value. 


\section{The Phillips Curve}

The Phillips curve, as in Smets-Wouters $(2003,2007)$ model, has both a forward-looking and a backward-looking component. The former comes directly from the New-Keynesian structure with rational agents, while latter does not come from micro-fundamentals and is aimed at capturing the presence of indexation mechanisms in the economy. Second, inflation depends on the output gap, $h_{t}$. In a more sophisticated setting, this would equal $y-y_{f}$ where the latter is the output attained when all nominal stickness is nonexistent and the former is the output obtained when the rigidities' parameters are turned on. Here, the output gap is treated as an observable variable: $\log (y)-H P$ filter_trend $(\log (y))$. Finally, inflation is also assumed to depend on the incidence of shocks, $\epsilon p_{t}$, like variations in the nominal exchange rates, oil prices, food-prices, firms' mark-ups, etc.

$$
\pi_{t}=\rho . \pi_{t-1}+(1-\rho) \pi_{t+1}^{e}+\beta . h_{t}+\epsilon p_{t}
$$

Again, since $\pi_{t}=\pi_{t, \text { actual }}-\bar{\pi}$, when the output gap is zero, inflation hits its steady-state level. In countries featuring a more explicit target for inflation, $\bar{\pi}$ would be equal to the target.

The (implicit?) Taylor Rule

Again, even if these countries didn't adopt interest rates as an instrument for most of the sample period studied, given a demand for money function, the government is implicitly choosing a path for interest rates by pinning down money growth Is this path well described 
by a typical Taylor rule? That is, does it depend on inflation, the output gap and on past interest rates? The answer has to be answered empirically through the estimation of the following equation.

$$
i_{t}=\lambda \cdot i_{t-1}+(1-\lambda) \cdot\left(\sigma_{\pi} \cdot \pi_{t}+\sigma_{h} \cdot h_{t}\right)+\sigma_{\Delta h} \cdot\left(h_{t}-h_{t-1}\right)+\epsilon r_{t}
$$

Notice that in the long-run, when $i_{t}=i_{t-1}$, the response of interest-rates to inflation is given by the coefficient $\sigma_{\pi}$ (long-run elasticity). If this is estimated to be greater than one, than the Taylor Principle is being followed - real interest rates increase to curb inflation - and inflation never spirals out of control. The interest rate equation also assumes the government reacts to both the output gap and its variation, and includes a term, $\lambda . i_{t-1}$, to account for the empirical fact that interest rates are persistent .

\section{Priors and shocks}

In any Bayesian estimation, model+priors +likelihood maximization using observables=posterior modes. Then after the posterior mode is found, a MCMC procedure is employed to generate the posterior distribution ${ }^{2}$. So choosing the priors is a crucial step, and to some extent, a very discretionary one.

The priors for the elasticity parameters $\beta$ and $\theta$ are assumed to follow a Normal distribution with average 1 and standard deviation of 0.5 . The relatively fat tails are important to allow the estimation procedure not to penalize parameters values far away from the prior mean. For the other parameters in all equations, I follow closely the assumptions made in Smets-Wouters (2007). The autoregressive terms - including the lagged interest rate in the Taylor Rule - are picked from Beta distributions with mean 0.75 and standard-deviation of

\footnotetext{
${ }^{2}$ For a thorough discussion see Dave and DeJong (2011).
} 
0.1. In the Taylor Rule the weight attributed to deviations of the inflation rate is $1.5^{3}$ and for the output gap, 0.25. Regarding these two parameters I assume larger initial standarddeviations. Instead of Smets-Wouters' 0.25 and 0.125 , I initiate the estimation with a standard deviation of 0.5 for both of them.

Finally, the shocks to each of the three equations are assumed to follow an autoregressive process themselves. So, $\epsilon i_{t}=\psi_{i} . \epsilon i_{t-1}+\Sigma_{i}$, where $i=p, h, r$ and $\Sigma_{i} \sim N\left(O, \vartheta_{i}\right)$.

\section{Discussion}

Here I present and discuss the results coming out from the Bayesian estimation of the simple model in Section 2.

\subsection{Estimations}

The results for Kenya using the 2000/2011 sample reveal that $\sigma_{\pi}$ is well above 1 . Further, it is nearly twice as large as the prior of 1.5: authorities appear to be on average reacting strongly to inflation deviations.

The key parameter in the Phillips curve, $\beta$, is close to 1.5, suggesting our simple measure of the output gap is highly correlated with inflation. In models 1 and 3, monetary transmission channels - captured by $\theta$ in the IS curve- are also operative and significant. Finally, the monetary authority seems to focus more on variations of the output gap than on the gap itself $^{4}$.

\footnotetext{
${ }^{3}$ I also experimented with priors closer to 1 for this parameter, but the results were nearly unchanged.

${ }^{4}$ The same holds in Smets-Wouters estimations for the US economy.
} 
Table 1: Kenya 2000-11

\begin{tabular}{|c|c|ccc|}
\hline Parameters & Priors & model 1: interbank rates & model 2: lending rates & model 3: Tbill rates \\
\hline \hline$\alpha$ & 0.75 & 0.96 & 0.94 & 0.96 \\
$\beta$ & 1 & 1.46 & 1.49 & 1.44 \\
$\varrho$ & 0.75 & 0.42 & 0.53 & 0.42 \\
$\theta$ & 1 & 0.18 & 0.06 & 0.17 \\
$\lambda$ & 0.75 & 0.74 & 0.78 & 0.76 \\
$\sigma_{-}\{\pi\}$ & 1.5 & 2.74 & 2.77 & 2.76 \\
$\sigma_{-}\{\mathrm{h}\}$ & 0.25 & 0.31 & 0.58 & 0.32 \\
$\sigma_{-}\{\Delta \mathrm{h}\}$ & 0.5 & 0.95 & 0.97 & 0.89 \\
$\psi_{-}\{\mathrm{p}\}$ & 0.75 & 0.51 & 0.54 & 0.53 \\
$\psi_{-}\{\mathrm{r}\}$ & 0.75 & 0.88 & 0.79 & 0.89 \\
\hline
\end{tabular}

Do these results change significantly with the inclusion of 2012 and 2013 in the estimations, the period following the landmark CBs meeting reported in Berg et al (2013)? As the next table suggests, apparently not much in the case of Kenya. The $\sigma_{\pi}$ coefficient does increase, but the rise is tiny. Nevertheless, this has to be qualified by the fact that only eight data points are being added to a sample of fifty.

Table 2: Kenya 2000-13

\begin{tabular}{|c|c|ccc|}
\hline Parameters & Priors & model 1: interbank rates & model 2: lending rates & model 3: Tbill rates \\
\hline \hline$\alpha$ & 0.75 & 0.96 & 0.96 & 0.96 \\
$\beta$ & 1 & 1.56 & 1.52 & 1.48 \\
$\varrho$ & 0.75 & 0.41 & 0.38 & 0.42 \\
$\theta$ & 1 & 0.17 & 0.18 & 0.18 \\
$\lambda$ & 0.75 & 0.74 & 0.76 & 0.75 \\
$\sigma_{-}\{\pi\}$ & 1.5 & 2.83 & 2.8 & 2.86 \\
$\sigma_{-}\{\mathrm{h}\}$ & 0.25 & 0.38 & 0.26 & 0.33 \\
$\sigma_{-}\{\Delta \mathrm{h}\}$ & 0.5 & 0.9 & 0.84 & 0.92 \\
$\psi_{-}\{\mathrm{p}\}$ & 0.75 & 0.52 & 0.52 & 0.5 \\
$\psi_{-}\{\mathrm{r}\}$ & 0.75 & 0.89 & 0.76 & 0.88 \\
\hline
\end{tabular}

The story is quite similar for Uganda. The response of interest rates to inflation is in the same ballpark, as are the Phillips Curve and IS elasticities. As previously, including 2012 and 2013 leads to a small increase in the posterior modes of $\sigma_{\pi}$. However, now the weights attributed to the output gap and its variation change a lot in accordance to the measure of interest rates employed. 
Table 3: Uganda 2000-11

\begin{tabular}{|c|c|ccc|}
\hline Parameters & Priors & model 1: interbank rates & model 2: lending rates & model 3: Tbill rates \\
\hline \hline$\alpha$ & 0.75 & 0.94 & 0.97 & 0.95 \\
$\beta$ & 1 & 1.45 & 1.35 & 1.49 \\
$\varrho$ & 0.75 & 0.51 & 0.22 & 0.49 \\
$\theta$ & 1 & 0.2 & 0.21 & 0.22 \\
$\lambda$ & 0.75 & 0.75 & 0.71 & 0.73 \\
$\sigma_{-}\{\pi\}$ & 1.5 & 2.66 & 1.97 & 2.72 \\
$\sigma_{-}\{\mathrm{h}\}$ & 0.25 & 0.34 & -0.48 & 0.27 \\
$\sigma_{-}\{\Delta \mathrm{h}\}$ & 0.5 & 0.6 & 0.12 & 0.51 \\
$\psi_{-}\{\mathrm{p}\}$ & 0.75 & 0.44 & 0.47 & 0.46 \\
$\psi_{-}\{\mathrm{r}\}$ & 0.75 & 0.83 & 0.96 & 0.87 \\
\hline
\end{tabular}

Table 4: Uganda 2000-13

\begin{tabular}{|c|c|ccc|}
\hline Parameters & Priors & model 1: interbank rates & model 2: lending rates & model 3: Tbill rates \\
\hline \hline$\alpha$ & 0.75 & 0.94 & 0.97 & 0.95 \\
$\beta$ & 1 & 1.51 & 1.48 & 1.56 \\
$\varrho$ & 0.75 & 0.48 & 0.25 & 0.47 \\
$\theta$ & 1 & 0.21 & 0.19 & 0.23 \\
$\lambda$ & 0.75 & 0.73 & 0.73 & 0.74 \\
$\sigma_{-}\{\pi\}$ & 1.5 & 2.74 & 2.36 & 2.78 \\
$\sigma_{-}\{\mathrm{h}\}$ & 0.25 & 0.36 & -0.34 & 0.31 \\
$\sigma_{-}\{\Delta \mathrm{h}\}$ & 0.5 & 0.59 & 0.1 & 0.55 \\
$\psi_{-}\{\mathrm{p}\}$ & 0.75 & 0.44 & 0.47 & 0.46 \\
$\psi_{-}\{\mathrm{r}\}$ & 0.75 & 0.77 & 0.95 & 0.88 \\
\hline
\end{tabular}

Thus, on average, the estimations for Uganda and Kenya look very much alike. As I show later, that similarity disappears when we look at the size of deviations from the Taylor Rule for each country.

Things are different for Tanzania: the overall fit of the model is much poorer, reflecting the widely-held view that countries authorities are less flexible in the pursuit of its money aggregate objectives. On the other hand, in Tanzania's case there seems to be more of an improvement after 2011. Not only the coefficient on inflation increases significantly with the inclusion of eight additional observations, but also the effectiveness of monetary policy captured by the term $\theta$ is three times higher. 
Table 5: Tanzania 2000-11

\begin{tabular}{|c|c|ccc|}
\hline Parameters & Priors & model 1: interbank rates & model 2: lending rates & model 3: Tbill rates \\
\hline \hline$\alpha$ & 0.75 & 0.99 & 0.99 & 0.96 \\
$\beta$ & 1 & 0.01 & 0.01 & 0.31 \\
$\varrho$ & 0.75 & 0.67 & 0.67 & 0.28 \\
$\theta$ & 1 & 0.04 & 0.02 & 0.55 \\
$\lambda$ & 0.75 & 0.8 & 0.86 & 0.58 \\
$\sigma_{-}\{\pi\}$ & 1.5 & 1.61 & 1.72 & 1.41 \\
$\sigma_{-}\{\mathrm{h}\}$ & 0.25 & 1.86 & 1.87 & -0.18 \\
$\sigma_{-}\{\Delta \mathrm{h}\}$ & 0.5 & 0 & 0.01 & 0.49 \\
$\psi_{-}\{\mathrm{p}\}$ & 0.75 & 0.56 & 0.53 & 0.13 \\
$\psi_{-}\{\mathrm{r}\}$ & 0.75 & 0.99 & 0.99 & 0.91 \\
\hline
\end{tabular}

Table 6: Tanzania 2000-13

\begin{tabular}{|c|c|ccc|}
\hline Parameters & Priors & model 1: interbank rates & model 2: lending rates & model 3: Tbill rates \\
\hline \hline$\alpha$ & 0.75 & 0.99 & 0.99 & 0.99 \\
$\beta$ & 1 & 0.58 & 0.47 & 0.01 \\
$\varrho$ & 0.75 & 0.19 & 0.11 & 0.68 \\
$\theta$ & 1 & 0.12 & 0.04 & 0.03 \\
$\lambda$ & 0.75 & 0.68 & 0.77 & 0.78 \\
$\sigma_{-}\{\pi\}$ & 1.5 & 2.57 & 2.43 & 1.51 \\
$\sigma_{-}\{\mathrm{h}\}$ & 0.25 & 0.07 & -0.15 & 1.94 \\
$\sigma_{-}\{\Delta \mathrm{h}\}$ & 0.5 & 0.03 & 0 & 0.01 \\
$\psi \_\{\mathrm{p}\}$ & 0.75 & 0.76 & 0.77 & 0.57 \\
$\psi_{-}\{\mathrm{r}\}$ & 0.75 & 0.99 & 0.99 & 0.99 \\
\hline
\end{tabular}

\subsection{Estimating the neutral rate instead of demeaning by the average}

In what follows, the only equation undergoing a specification change is the Taylor Rule. Instead of demeaning by the average, interest rates are now "demeaned" by a jointly estimated neutral rate, $r \_n$. This, in turn, is obtained via the Kalman Filter by adding to the system of equations above the following "state equation":

$$
r \_n_{t}=\zeta . r \_n_{t-1}+e n_{t}
$$

Where $r \_n_{t}$ is the non-observable neutral rate of interest and $e n_{t}$ is a shock with $N(0,1)$ distribution.

As the table below indicates, not much changes when the Kalman Filter is used to tease 
out the neutral rate of interest. ${ }^{5}$ It is worth noting again the huge changes in the estimators in Tanzania's case. After including 2012 and 2013 in the sample, the effectiveness of monetary policy increases dramatically $-\theta$ goes from close to zero to 0.72 - and so too the weight attributed to the inflation term in the Taylor Rule, which increases by a whopping $65 \%$.

Table 7: estimating neutral rates instead of demeaning

\begin{tabular}{|c|c|c|c|c|c|c|c|c|c|}
\hline \multicolumn{2}{|c|}{} & Kenya (neutral rates) & \multicolumn{3}{c|}{ Uganda (neutral rates) } & \multicolumn{3}{c|}{ Tanzania (neutral rates) } \\
\hline Parameters & Priors & Posterior 2011 & Posterior 2013 & Parameters & Posterior 2011 & Posterior 2013 & Parameters & Posterior 2011 & Posterior 2013 \\
\hline \hline$\alpha$ & 0.75 & 0.96 & 0.95 & $\alpha$ & 0.92 & 0.91 & $\alpha$ & 0.99 & 0.96 \\
$\beta$ & 1 & 1.43 & 1.47 & $\beta$ & 1.48 & 1.49 & $\beta$ & 0.03 & 0.28 \\
$\varrho$ & 0.75 & 0.44 & 0.43 & $\varrho$ & 0.51 & 0.46 & $\varrho$ & 0.64 & 0.29 \\
$\theta$ & 1 & 0.18 & 0.18 & $\theta$ & 0.23 & 0.22 & $\theta$ & 0.05 & 0.72 \\
$\lambda$ & 0.75 & 0.75 & 0.75 & $\lambda$ & 0.73 & 0.74 & $\lambda$ & 0.77 & 0.75 \\
$\sigma_{-}\{\pi\}$ & 1.5 & 2.81 & 2.83 & $\sigma_{-}\{\pi\}$ & 2.67 & 2.78 & $\sigma_{-}\{\pi\}$ & 1.59 & 2.41 \\
$\sigma_{-}\{\mathrm{h}\}$ & 0.25 & 0.43 & 0.41 & $\sigma_{-}\{\mathrm{h}\}$ & 0.37 & 0.4 & $\sigma_{-}\{\mathrm{h}\}$ & 1.85 & -0.13 \\
$\sigma_{-}\{\mathrm{Ah}\}$ & 0.5 & 0.98 & 0.95 & $\sigma_{-}\{\mathrm{Ah}\}$ & 0.59 & 0.6 & $\sigma_{-}\{\mathrm{Ah}\}$ & 0 & 0.22 \\
$\psi_{-}\{\mathrm{p}\}$ & 0.75 & 0.52 & 0.51 & $\psi_{-}\{\mathrm{p}\}$ & 0.45 & 0.46 & $\psi_{-}\{\mathrm{p}\}$ & 0.62 & 0.3 \\
$\psi_{-}\{\mathrm{r}\}$ & 0.75 & 0.85 & 0.86 & $\psi_{-}\{\mathrm{r}\}$ & 0.78 & 0.75 & $\psi_{-}\{\mathrm{r}\}$ & 0.99 & 0.91 \\
\hline
\end{tabular}

\subsection{Taylor Principle vs Taylor Rule}

Now, it is one thing to abide by the Taylor Principle on average, quite another to closely follow the Taylor Rule through time. But how should one go about judging whether the observed deviations from the Taylor Rule are excessive or not? There is no simple answer for that question. Here, the strategy adopted is to compare the deviations, $\epsilon r_{t}$, for each of the three countries, to the same deviations observed in two formal Inflation Targeters - Brazil and South Africa.

\footnotetext{
${ }^{5}$ Here I present the results only for the interbank rate.
} 
Table 8: Brazil and South Africa

\begin{tabular}{|c|c|c|c|c|}
\hline \multicolumn{3}{|c|}{ Brazil } & \multicolumn{2}{c|}{ South Africa } \\
\hline Parameters & Priors & Posterior 2013 & Priors & Posterior 2013 \\
\hline \hline $\boldsymbol{\beta}$ & 0.75 & 0.94 & 0.75 & 0.87 \\
$\rho$ & 1 & 0.56 & 1 & 1.62 \\
$\Theta$ & 0.75 & 0.82 & 0.75 & 0.81 \\
$\lambda$ & 1 & 1.39 & 1 & 1.28 \\
$\boldsymbol{\sigma}\{\boldsymbol{\tau}\}$ & 0.75 & 0.43 & 0.75 & 0.39 \\
$\sigma \_\{h\}$ & 1.5 & 3.41 & 1.5 & 3.33 \\
$\sigma \_\{\Delta \text { h }$ & 0.25 & 0.31 & 0.25 & 0.6 \\
$\Psi \_\{p\}$ & 0.5 & 0.25 & 0.5 & 0.79 \\
$\Psi \_\{r\}$ & 0.75 & 0.57 & 0.75 & 0.41 \\
\hline
\end{tabular}

Since interest rate levels differ, a better measure of non-adherence to the Taylor Rule is given by the standard-deviation of the error term, $\epsilon r_{t}$, divided by the interest rate $i_{t}$. As the charts below reveal, Uganda's deviations are much smaller than the ones for Kenya and Tanzania, and nearly identical to Brazil's. More surprisingly, Taylor Rule deviations in Uganda - a nouveau Targeter - are somewhat smaller than those found for South Africa, which has relied on this framework since 2000.

The opposite holds for Tanzania: in spite of its $\sigma_{\pi}>1$, the huge deviations from the Taylor Rule suggest the country has not consistently resorted to interest rates as an instrument to achieve its inflation goals. Nevertheless, this is due to large oscillations in $\epsilon r_{t} / i_{t}$, in the first years of the sample period, with things getting much more stable after 2005. Kenya, in turn, is an intermediate - and somewhat odd - case. Its relatively high coefficient of variation has its roots in three isolated and abnormal episodes: one spectacular contractionary movement in 2003, a countervailing lax policy in 2004 and then again a significant loosening in 2011. 
Fig.3: Normalized Taylor Rule's Residuals

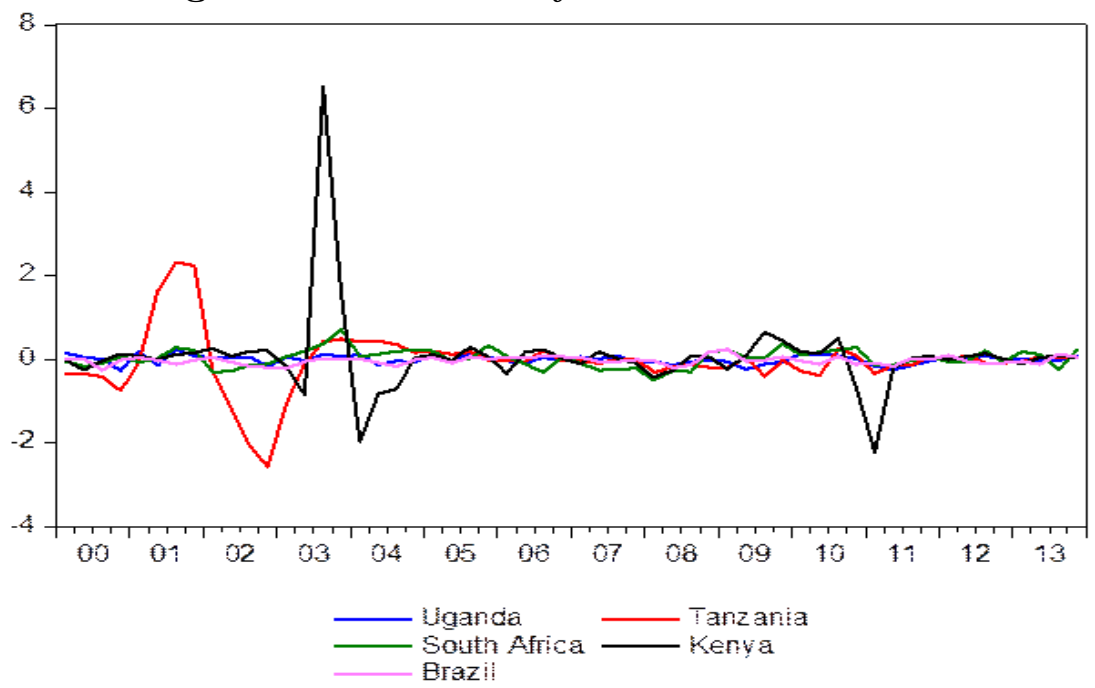

Fig.4: Normalized Taylor Rule's Residuals - Brazil and Uganda (scale: a order

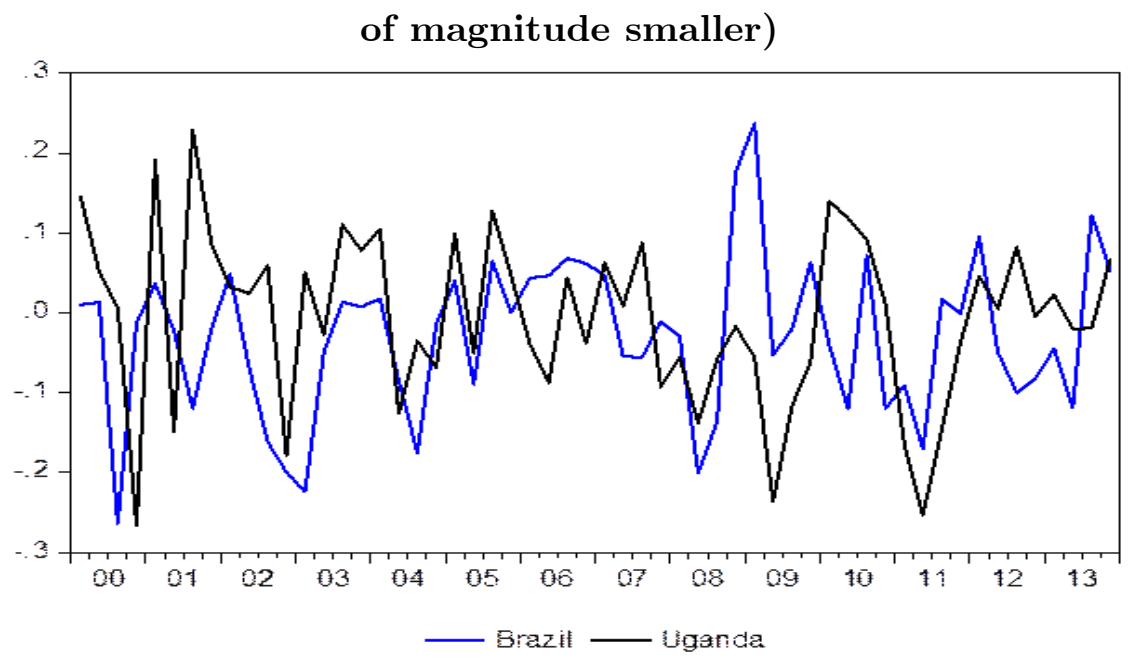

Fig.5: Normalized Taylor Rule's Residuals - Uganda and South Africa

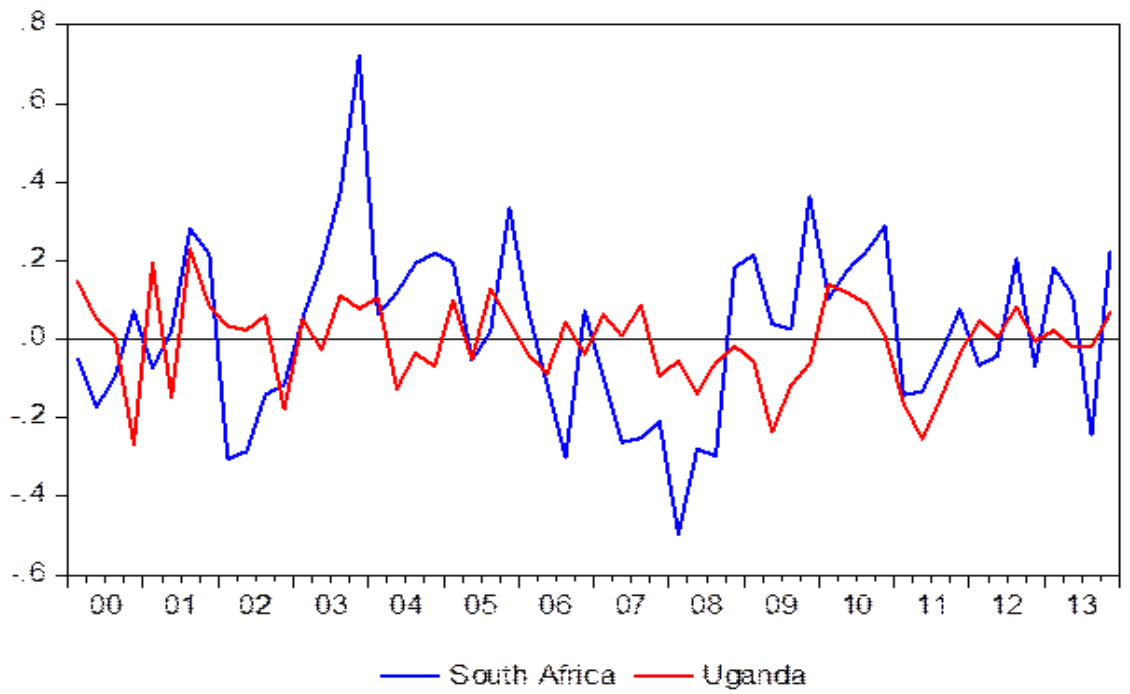

(C) International Monetary Fynd. Not for Redistribution 


\section{Final comments}

Estimation of small-scale models for Kenya, Uganda and Tanzania reveals that monetary policy in these countries respects the Taylor Principle, that is, on average nominal interest rates have been pushed higher by more than one-to-one with inflation by these countries' central banks. For Uganda and Kenya, the estimated weights attributed to inflation deviations in authorities' reaction functions do not seem to have changed much after the 2011 CBs meeting. In these two countries the story seems to be that monetary conditions got tighter after 2011 because inflation went up. However, this is not the case for Tanzania, since the parameter linking interest rates to inflation jumps considerably when one includes the after-2011 period in the sample.

But even if these countries are implementing the Taylor Principle, deviations from the Taylor Rule in Kenya and Tanzania are far from negligible, reminiscent of money target strategies. Not so for Uganda, though, for whom the normalized error term is much smaller, and in fact, smaller then those found for South Africa, the older Inflation Targeter in that continent.

\section{References}

[1] Adam, Christopher. "The conduct of monetary Policy in Uganda: An Assessment" Economic Policy Research Centre Paper 65, 2009.

[2] Berg, Andrew; Charry, Luisa; Portillo, Rafael and Vlcek, Jan. "The Monetary Transmission Mechanism in the Tropics: A Narrative Approach", IMF Working Paper, 2013.

[3] Dave, Chetan and De Jong, David. "Structural Macroeconometrics", Princeton University Press, 2nd edition, 2011. 
[4] Mankiw, Nicholas G. "US Monetary Policy During the 90s", in Frankel, Jefrey and Peter Orszag (eds.) American Economic Policy in the 1990s. Cambridge, MA: MIT Press, 2002.

[5] Friedman, Milton. "The Methodology in Positive Economics", in Essays in Positive Economics, Chicago Press, 1953.

[6] Smets, Frank and Wouters, Rafael. "Shocks and Frictions in US Business Cycles: A Bayesian DSGE Approach", The American Economic Review, Vol. 97, No. 3, pp. 586606, 2007.

[7] Smets, Frank and Wouters, Rafael. "An Estimated Dynamic Stochastic General Equilibrium Model of the Euro Area." Journal of the European Economic Association, 1(5): 1123-75, 2003. 